\title{
Drastic structure changes in pre-damaged GaAs crystals irradiated with swift heavy ions
}

\author{
F. Komarov ${ }^{\mathrm{a}, *}$, V. Uglov ${ }^{\mathrm{b}}$, L. Vlasukova ${ }^{\mathrm{b}}$, A. Didyk ${ }^{\mathrm{c}}$, S. Zlotski ${ }^{\mathrm{b}}$, V. Yuvchenko $^{\mathrm{a}}$ \\ a Institute of Applied Physics Problems, Kurchatov Str. 7, 220045 Minsk, Belarus \\ ${ }^{\mathrm{b}}$ Belarusian State University, Nezavisimosti Ave. 4, 220030 Minsk, Belarus \\ ${ }^{\mathrm{c}}$ Flerov Laboratory of Nuclear Reactions, JINR, 141980 Dubna, Russia
}

\section{A R T I C L E I N F O}

\section{Article history:}

Received 30 March 2015

Received in revised form 18 August 2015

Accepted 21 August 2015

Available online 5 September 2015

\section{Keywords:}

Swift heavy ions

Gallium arsenide

Electron pre-damaging

Defect formation

\begin{abstract}
A B S T R A C T
We have studied structural transformations in pre-damaged GaAs crystals irradiated with high-energy Bi ions $\left(710 \mathrm{MeV}, 4.3 \times 10^{12} \mathrm{~cm}^{-2}\right)$. The pre-damage has been created via irradiation with swift electrons ( $4 \mathrm{MeV}, 4 \times 10^{17} \mathrm{~cm}^{-2}$ ). A structural disorder in irradiated samples has been investigated by means of selective chemical etching (SCE) and X-ray diffraction (XRD) in combination with the material layerby-layer removal. Character of lattice deformation in the double-irradiated sample gives an evidence of subsurface region's swelling. Strong lattice distortion has been found in the region of Bi ion ranges at the depth of about $30 \mu \mathrm{m}$. The nature of this effect is discussed.
\end{abstract}

(c) 2015 Published by Elsevier B.V.

\section{Introduction}

The interest in studying the interaction of swift heavy ions (SHI) with semiconductors is due to a possible use of SHI for creation of nanostructures, such as nanoclusters or nanotubes, in various materials. The damage in semiconductor devices of nuclear reactors, superhigh energy accelerators or in outer space equipment can be studied using swift heavy ions, too. And last, but not least, is an issue of the influence of the electronic and nuclear energy deposition on the structural modifications of semiconductors during irradiation. Damage formation and amorphization of semiconductors may be caused both by the nuclear and electronic interaction processes which are going on simultaneously with different efficiency depending on mass and energy of the incident ion for a given material [1]. A way to divide the contribution of electronic and nuclear energy deposition into the structural transformation caused by ion irradiation is the use of swift heavy ions. At high ion energies, the depth regions of dominating electronic and nuclear interaction are clearly separated. Presently, the basic physical mechanisms of damage formation in semiconductors due to SHI irradiation are not yet fully clear. Last decades, the researcher's efforts were focused mainly on studying the specific damaged regions called latent tracks. The heavily damaged or amorphous tracks are formed in some semiconductors in the range of depths where electronic energy losses of SHIs dominate [2-9],

\footnotetext{
* Corresponding author.
}

and the energy received by the target atoms through the nuclear interactions is negligible. However, in such crystals as $\mathrm{Si}, \mathrm{Ge}$ and GaAs, the extremely high level of electronic energy deposition is required in order to form amorphous tracks [10-12]. For such materials, the damage production due to nuclear energy loss at the end of ion trajectories can become the principal mechanism. Thus, the investigation of damage depth profile in semiconductors irradiated with SHIs is of great importance for the understanding of radiation damage accumulation and recovery. Though, there are quite a few reports in the literature on the damage depth profiling of SHI-irradiated semiconductors. So, Belekar et al. reported the damage depth distribution of $70 \mathrm{MeV}-{ }^{56} \mathrm{Fe}$ implanted GaAs observed by successive polishing etching of the irradiated sample and near-mid IR spectroscopy [13]. Recently, Wang with colleagues [14] performed Raman spectroscopy measurements of the cross-sections of $6 \mathrm{H}-\mathrm{SiC}$ irradiated with $20 \mathrm{MeV}$ carbon ions in order to study the depth damage profile.

It has been found that previous disordering stimulates the track formation processes in crystalline InP and GaAs [3,8]. Earlier, studying the influence of pre-damaging on the track formation, we have discovered a region of heavy mechanical damage (microcracks) in the crystalline GaAs firstly irradiated with electrons $\left(4 \mathrm{MeV}, 4 \times 10^{17} \mathrm{e}^{-} / \mathrm{cm}^{2}\right)$, and afterwards with swift ions of ${ }^{209} \mathrm{Bi}$ (710 MeV, $1 \times 10^{12} \mathrm{Bi}^{+} / \mathrm{cm}^{2}$ ). This region was located at a depth exceeded the projected range of $\mathrm{Bi}$ ions [15]. The abovediscussed effect is not observed for the samples irradiated with Bi ions alone. 
The radiation damage was revealed using the selective chemical etching (SCE) technique. SCE is a standard method for defining the dislocation density in semiconductor crystals. This technique includes a treatment of crystalline sample in selective etchant followed by the investigation of etched surface in a microscope. The local differences in the etch rate are induced by the deformation fields around defects (e.g. strain fields of dislocations). These etch rate differences result in topographic changes of the etched surface and in appearance of defect-related etch features (pits, hillocks or more complicated features) which are then observed using the optical, scanning electron or atomic force microscopy. It should be emphasised that such defects are not directly visible and a nature of chemical inhomogeneities cannot be defined solely by etching in a straightforward way. Therefore, SCE has to be considered as an indirect method, and, as a rule, comparison with other direct methods (e.g. transmission electron microscopy or X-ray diffraction) has to be used for defect interpretation or quantitative evaluation. This drawback is compensated by several advantages, such as inexpensive and simple equipment, short time of data acquisition, very broad range of defects which are revealed by this technique. Due to the vital demand for quick and reliable characterization techniques for revealing defects in crystalline semiconductors, sophisticated etching procedures have been developed, e.g. photo-etching of $A^{3} B^{5}$ and wide gap semiconductors $[16,17]$. As the result, apart of routine etch pit density counting, it is possible to study the crystallographic and chemical ingomogeneties in bulk crystals, epitaxial layers and, in some cases, in the complete device structures by means of SCE. We have adapted this technique to reveal the structural damage in crystalline semiconductors irradiated with swift heavy ions [6,7].

The aim of this paper is to study the damage depth profile in GaAs double-irradiated with MeV electrons and swift Bi ions by means of SCE and X-ray diffraction (XRD) analysis in combination with the layer-by-layer removal of the sample's material.

\section{Experimental}

The initial samples of $(1 \times 1) \mathrm{cm}^{2}$ size were cut out from the semi-insulating (100) GaAs wafer with thickness of about $300 \mu \mathrm{m}$. Afterwards, the samples were irradiated at room temperature with $4 \mathrm{MeV}$ electrons to a fluence of $4 \times 10^{17} \mathrm{~cm}^{-2}$ at the Laboratory of Radiation Interactions of Scientific and Practical Materials Research Centre of the Belarusian National Academy of Sciences. Then, a part of electron irradiated samples were bombarded at normal incidence with $710 \mathrm{MeV}-{ }^{209} \mathrm{Bi}$ ions to a fluence of $4.3 \times 10^{12} \mathrm{~cm}^{-2}$ at the $\mathrm{U} 400$ isochronous cyclotron of the Joint Institute for Nuclear Research in Dubna (Russia). The sample temperature during irradiations did not exceed $50{ }^{\circ} \mathrm{C}$. The electronic energy loss $\left(S_{e}\right)$ at the entry in GaAs and the mean projected range $\left(\bar{R}_{p} \pm \Delta \bar{R}_{p}\right)$ of Bi ions were calculated with the SRIM 2010 computer code and amounted to $35.7 \mathrm{keV} / \mathrm{nm}$ and $30.8 \pm 1.1 \mu \mathrm{m}$, respectively.

The radiation damage was studied by the selective chemical etching of cross-sections (cleaves) of the irradiated GaAs samples. The pieces of material of $(0.1-0.15) \times 1 \mathrm{~cm}^{2}$ size were split off the samples perpendicular to the surface in order to get such cleaves. Then, these cleaves were treated in the selective $A B$-etchant $\left\{\mathrm{CrO}_{3}(10 \mathrm{~g})+\mathrm{H}_{2} \mathrm{O}(20 \mathrm{ml})+\mathrm{HF}(10 \mathrm{ml})+\mathrm{AgNO}_{3}(0.08 \mathrm{~g})\right\}[18] . \mathrm{AB}-$ etchant is applied to reveal impurities or defect inhomogeneities and epilayer interfaces in $A^{3} B^{5}$ materials $[19,20]$. Etching was performed for $10-20 \mathrm{~s}$ at the room temperature. The layers with thickness of $\sim 0.1-0.2 \mu \mathrm{m}$ were etched away during the selective etching. Afterwards, the treated surfaces were investigated with the optical microscope Leica INM-100 using interference contrast and, in some cases, with the scanning electron microscope Hitachi
S-806. On the whole, a procedure is simple and quick. Moreover, it gives a possibility to get information on damage distribution along the whole ion trajectory in the same experiment. It is especially important because the projected range of swift ions with energies of $500-700 \mathrm{MeV}$ exceeds $20-30 \mu \mathrm{m}$ for the most of semiconductors.

Besides that, the high resolution XRD technique was used in order to determine GaAs lattice distortions initiated by irradiations. XRD measurements were carried out using DRON 4.0 diffractometer with $\mathrm{CuK}_{\alpha 1}$ radiation $\left(\lambda_{\text {mean }}=1.54179 \AA\right.$ ). According to [21] the GaAs (004) reflection is sensitive to strain in the vertical layer structure. The X-ray penetration depth in this case reaches about $5 \mu \mathrm{m}$. According to our preliminary measurements, the XRD GaAs (006) reflection is also sensitive to such strain. That is why, diffraction patterns in our study were measured at both (004) and (006) GaAs reflections. In order to study lattice distortion depth profiles, XRD measurements were carried out at different depth by successive polishing etching of the samples in the etchant $\mathrm{H}_{2} \mathrm{SO}_{4}: \mathrm{H}_{2} \mathrm{O}_{2}: \mathrm{H}_{2} \mathrm{O}$ with the volume ratio of $3: 1: 1$.

\section{Results and discussion}

It should be mentioned that Frenkel pairs $\left(V_{A s}-A s_{i}\right)$ are primary radiation defects produced in GaAs crystals during an electron irradiation at room temperature. Contrary to $\mathrm{Si}$ and $\mathrm{Ge}$ crystals, the process of point defect annihilation in GaAs is negligible due to a low mobility of point defects at the room temperature [22]. The ranges of electrons with an energy of $1 \mathrm{MeV}$ and higher in basic semiconductors (like Si or GaAs) exceed the thickness of samples used in our experiment [23]. Taking this it into account, we can consider isolated Frenkel pairs as the main radiation defects produced in GaAs under the irradiation with swift electrons. Frenkel pairs are created by electrons uniformly through the whole sample with the concentration in proportion to electron fluence. For our experiment, the calculated concentration of Frenkel pairs produced by electron irradiation amounts to $8.5 \times 10^{18} \mathrm{~cm}^{-3}$.

Fig. 1 depicts the depth profiles of energy deposition into electronic and nuclear subsystems of GaAs as well as vacancies and embedded $\mathrm{Bi}$ atoms depth distributions. One can see that electronic energy deposition in the range of depth from 0 to $5 \mu \mathrm{m}$ is nearly constant and amounts to $35 \mathrm{keV} / \mathrm{nm}$. This value is of about 2 orders of magnitude higher than nuclear energy deposition for the same depth range. The electronic (nuclear) energy deposition decreases (increases) with the depth increase, and becomes the

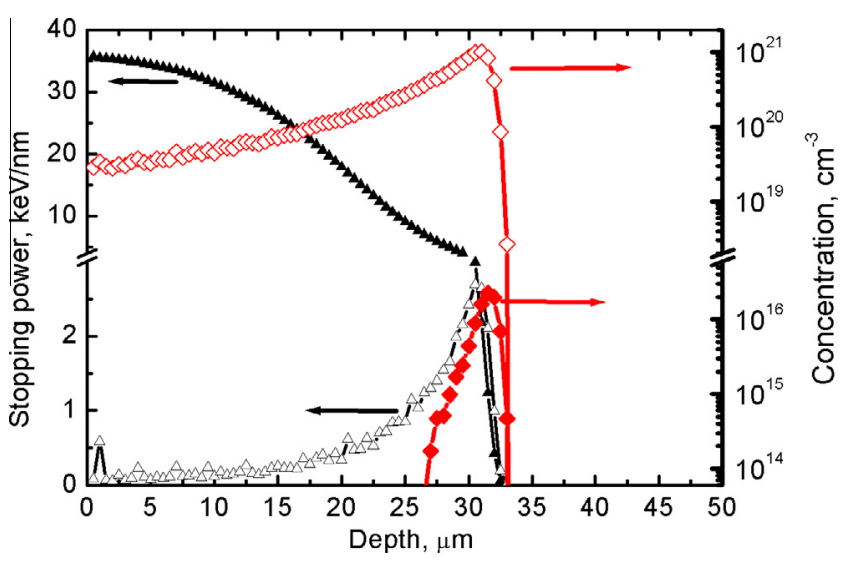

Fig. 1. Calculated according to SRIM'2010 code [24] data for the energy deposition in ionisation processes (electronic energy loss $\left.S_{e}\right)\left(-\mathbf{\Delta}^{-}\right)$and in displacements (nuclear energy loss $\left.S_{n}\right)(-\triangle$-) as well as the concentrations of embedded Bi atoms $\left(-\diamond_{-}\right)$and vacancies $\left.(-\rangle_{-}\right)$as a function of depth for GaAs crystal irradiated with $\mathrm{Bi}$ ions $\left(710 \mathrm{MeV}, 4.3 \times 10^{12} \mathrm{Bi}^{+} / \mathrm{cm}^{2}\right)$. 
same value at the depth of $31 \mu \mathrm{m}$. The vacancy concentration reaches the highest value of $\approx 1 \times 10^{21} \mathrm{~cm}^{-3}$ at the depth of $\approx 31 \mu \mathrm{m}$ while the $\mathrm{Bi}$ atoms concentration at the end of range is $\approx 2 \times 10^{16} \mathrm{~cm}^{-3}$.

Fig. 2 shows the depth distribution of radiation damage in GaAs revealed by SCE. It should be noted that there are no track-type damage at the whole range of depth where the electronic energy deposition of $\mathrm{Bi}$ ions is dominating. This observation can be explained via track overlapping and damage annealing in our experiment conditions. Earlier [7], we have registered the track formation in GaAs crystals irradiated with $710-\mathrm{MeV}$ Bi ions. The tracks were registered by atomic force microscopy and SCE. The tube-like track signs with the length of $\sim 20-25 \mu \mathrm{m}$ were visible on the etched cross-sections of the samples irradiated with low ion fluence (up to $5 \times 10^{10} \mathrm{~cm}^{-2}$ ). The fluence increase up to $1 \times 10^{12} \mathrm{~cm}^{-2}$ resulted in the disappearance of track-type signs from the etched cross-sections. We ascribed this effect to the track overlapping and annealing of damage formed at early stages of irradiation.

There are two damaged layers on the etch pattern of the sample irradiated with Bi ions only, (Fig. 2a). These layers are revealed as small-dotted background regions. The first one is situated at a depth of $25-30 \mu \mathrm{m}$. Its location is in a reasonable agreement with the predicted maximum of concentration depth profile for vacancies produced by Bi ions (Fig. 1). As we mentioned above, it is not possible to detect individual point defects by SCE. However, defect complexes (aggregates of vacancies, for example) could be revealed via etching procedure as small etch pits [25]. Taking it into account, one could interpret defects revealed as small dots in the first defect layer as vacancies aggregates.

The second damaged layer is located at a depth of $43-48 \mu \mathrm{m}$. This depth amounts to $\approx 1.4-1.5 R_{p}$. We can assume a relatively low level of damage in these layers as a low contrast at the etch pattern is observed. Presumably, an appearance of the defect layer at the depth range of $43-48 \mu \mathrm{m}$ can be caused by the effect of stopping of primary displaced Ga and As atoms as well as by channelling of a part of $\mathrm{Bi}$ ions and displaced $\mathrm{Ga}$ and $\mathrm{As}$ atoms through the tracks at the early stages of the irradiation [26]. The Table 1 presents the maximum values of energy transferred from $710 \mathrm{MeV}-\mathrm{Bi}$ ions to $\mathrm{Ga}$ and As recoils and corresponding mean projected ranges of this particles. It means that such recoils are formed at the sample surface.

The transferred energy was calculated using a formula [27]:

$E_{i, \max }=\frac{4 M_{B i} M_{i}}{\left(M_{B i}+M_{i}\right)^{2}} E_{B i}$,

where $E_{i, \text { max }}$ is the maximum value of energy transferred to lattice atom; $M_{i}$ is the lattice atom mass; $E_{B i}$ and $M_{B i}$ are the bismuth ion energy and mass, respectively.

One can see that calculated projected ranges of primary displaced Ga and As atoms generated in near-surface region are in a reasonable agreement with the location of the second defect layer on the etch pattern (Fig. 2a). Like in the case of Bi ions irradiation, it can expect that Ga and As recoils create significant amount of vacancies before stopping. By analogy with the first defect layer, we can suggest that defects composed the second damaged layer are vacancy complexes.

Of course, generation of recoils in close collisions of $\mathrm{Bi}$ ions with Ga and As matrix atoms takes place not only at the sample surface but in deeper regions, too. Though, according to our calculations (Fig. 3), only a near-surface layer of the sample (up to $5 \mu \mathrm{m}$ in Fig. 3) contributes recoils to the discussed damaged layer at the depth range of $43-48 \mu \mathrm{m}$. It should be noted that a part of recoils is stopped in the region between two observed bands of damages but a damage level in this intervening region is under a critical level to be found out by SCE.

The pre-irradiation of GaAs with swift electrons before SHI irradiation results in impressive structural changes (Fig. 2b). A layer included light, black and then bright band is observed at the depth of $25-30 \mu \mathrm{m}$. We failed to get a clear contrast of this region with the optical or scanning electron microscopes because of a complicated topography. Though, one can suggest that substantial strains were developed in this zone. A region of heavy mechanical damage is visible on the cross-section in a depth region of $\approx 30-40 \mu \mathrm{m}$. The damaged region contains the microcracks oriented at an angle of about $40^{\circ}$ with respect to the cleaved surface. The distance between the microcracks amounts nearly to $2.6 \mu \mathrm{m}$. The formation of such zones is not observed neither for the samples irradiated with electrons (not shown) nor for the samples irradiated with $\mathrm{Bi}$ ions, only (Fig. 2a). It should be noted that micro-cracking takes place just between two damaged layers observed in the only $\mathrm{Bi}$ irradiated sample. Moreover, the micro-cracks orientation at $\sim 40^{\circ}$ with respect to the cleaved (011) surface is close enough to the angle of $45^{\circ}$ originated from the cubic symmetry of GaAs (100) substrate [28]. Though, a detailed discussion of factors governing cracking in GaAs crystals is beyond the scope of this paper.

In order to clarify a nature of this effect and estimate a level of crystal lattice deformation we have investigated the doubleirradiated GaAs samples as well as virgin ones using X-ray diffraction in combination with the material layer-by-layer etching. Fig. 4 presents the XRD patterns of double-irradiated sample registered from different depth.

A substantial distortion of diffraction peaks has been found when the thickness of etched layer was in the range of 25$28 \mu \mathrm{m}$ (Fig. 4). The diffraction peak distortion is already negligible if the etched layer thickness exceeds $\sim 45 \mu \mathrm{m}$. This distortion of diffraction peak evidences the existence of a crystal region with heavy mechanical damage. It is in a good agreement with the cross-section microstructure (Fig. 2b). A lattice deformation for the different depth of double-irradiated sample has been determined from XRD data. A relative change of lattice inter-plane distances $\Delta d / d$, where $\Delta d=d-d_{0}, d_{0}$ is the inter-plane distance for the virgin sample, and $d$ is the inter-plane distance of irradiated sample on the different depths, have been taken as a level of lattice deformation.

Fig. 5 depicts the level of crystal lattice deformation as a function of the etched layer thickness for irradiated samples.

It should be noted that $\Delta d / d$ does not exceed $\pm 0.2 \%$ in the whole range of etched thickness for the sample irradiated with electrons only. This is an expectable result as swift electrons passing through the sample with the energy of $4 \mathrm{MeV}$ and a fluence of $4 \times 10^{17} \mathrm{~cm}^{-2}$ produce point defects with the concentrations of $\sim 10^{18} \mathrm{~cm}^{-3}$ uniformly. On the contrary, the electron irradiation followed with $\mathrm{Bi}$ ion irradiation results in an increase of the lattice inter-plane distance up to $(0.3-0.4) \%$ in the subsurface region of the sample. Here, "subsurface" means the layer between surface and the first damaged layer. The level of lattice deformation increases with etched layer thickness and achieves a highest value of $+(1.0-1.2) \%$ at the etched layer thickness of about $25 \mu \mathrm{m}$. A penetration depth of X-rays in our experiment is about $5 \mu \mathrm{m}$. Thus, according to XRD data a damaged region is located at the depth of about $25-30 \mu \mathrm{m}$. This depth range corresponds to the region of maximum vacancies concentration and end-of-range $\mathrm{Bi}$ ions (Fig. 1). The deformation level decreases to the values less than that in the subsurface region with the further increase of etched layer thickness (Fig. 5).

Below, an attempt is made to explain the observed effects. In our opinion, two possible mechanisms can be proposed. The first one is following. $\Delta d / d_{0}$ increase in the subsurface region can be attributed to a high concentration of vacancies. These point defects 

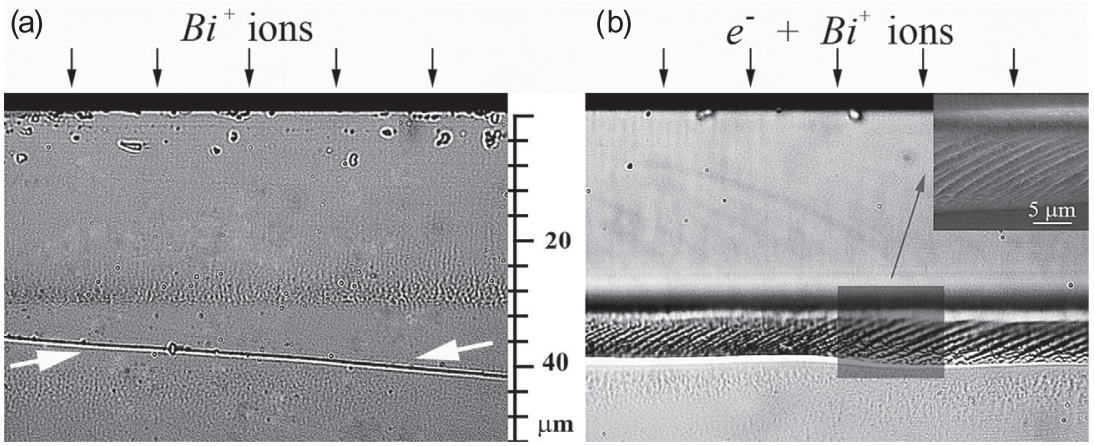

$\mathrm{a}-\mathrm{Bi}\left(710 \mathrm{MeV} ; 4.3 \times 10^{12} \mathrm{~cm}^{-2}\right) ; \mathrm{b}-\overline{\mathrm{e}}\left(4 \mathrm{MeV} ; 4 \times 10^{17} \mathrm{~cm}^{-2}\right)+\mathrm{Bi}\left(710 \mathrm{MeV} ; 4.3 \times 10^{12} \mathrm{~cm}^{-2}\right)$

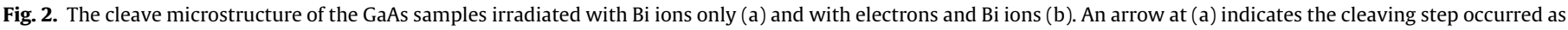
a result of mechanical damage during sample splitting off. Inset at (b) shows the magnified (scanning electron microscopy) image of the region outlined by rectangle.

Table 1

Energies of primary displaced Ga and As atoms and corresponding mean projected ranges for these recoils.

\begin{tabular}{lll}
\hline Ion type & $E, \mathrm{MeV}$ & $\bar{R}_{p} \pm \Delta \bar{R}_{p}, \mu \mathrm{m}$ \\
\hline $\mathrm{Bi}$ & 710 & $30.8 \pm 1.1$ \\
$\mathrm{Ga}$ & 534 & $50.5 \pm 1.6$ \\
$\mathrm{As}$ & 552 & $48.1 \pm 1.6$ \\
\hline
\end{tabular}

are mainly produced in the GaAs crystal at the stage of preliminary electron irradiation as well as at the stage of $\mathrm{Bi}$ ion irradiation (Fig. 1). It can be noted that such damages results in a lattice expansion [29]. Radiation swelling results in a development of mechanical strains in the GaAs subsurface region. A layer enriched with $\mathrm{Bi}$ atoms and damages can also serve as a getter for generated defects (preferably vacancies) from a crystal's volume produced at the stage of preliminary irradiation with electrons. Additionally, it should be marked that the interstitial recoils can be absorbed by this getter layer, too. As it was shown by Pillucat et al. [30] Ga-interstitial atoms are mobile in ê-irradiated GaAs at room temperature. As a result, the region with a high concentration of defects is formed under the layer with stopped $\mathrm{Bi}$ atoms. This region is characterised with low mechanical hardness, and begins to destroy because of a strain caused by subsurface layer radiation swelling.

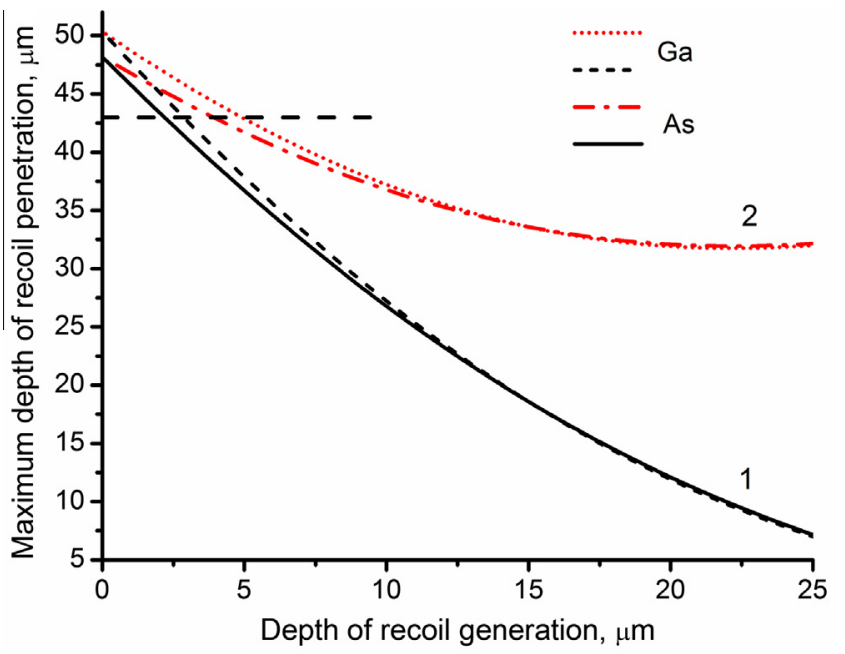

Fig. 3. Projected range of recoils (1) and maximum depth of recoil penetration in the irradiated sample (2) versus depth of recoil generation calculated using SRIM'2010 code. Dashed line coincides with the beginning of the second damaged layer at the depth of $43-48 \mu \mathrm{m}$.
Radiation swelling was reported for a number of ionic crystals such as $\mathrm{LiF}$ and $\mathrm{CaF}_{2}$ as well as for crystals with covalent bonding like $\mathrm{SiO}_{2}, \mathrm{Y}_{3} \mathrm{Fe}_{5} \mathrm{O}_{12}$ and $\mathrm{Gd}_{3} \mathrm{Ga}_{5} \mathrm{O}_{12}$ irradiated with SHIs [31]. This effect becomes noticeable at a fluence of $\sim 10^{11} \mathrm{~cm}^{-2}$. Sometimes, the irradiated layers of insulators split out of the underlying undamaged crystal at a fluence of $\sim 10^{13} \mathrm{~cm}^{-2}$. In our experiment, a level of mechanical stress is insufficient to destroy GaAs crystal during the irradiation with $\mathrm{Bi}$ ions at a fluence of $4.3 \times 10^{12} \mathrm{~cm}^{-2}$. Though, preliminary disordering of GaAs crystal via electron irradiation may facilitate material destruction during $\mathrm{Bi}$ ion bombardment, and the irradiated layer begins to split off already at a fluence of $4.3 \times 10^{12} \mathrm{~cm}^{-2}$.

Let us discuss the other possible mechanism. High-energy $\mathrm{Bi}$ ions can induce the formation of a buried amorphous layer in the pre-irradiated with electrons GaAs crystal in the region of high nuclear energy loss $S_{n}$ (end-of-range region). A total nuclear energy loss deposited in this region by $\mathrm{Bi}$ ions is described by the formula:

$\varepsilon=N S_{n}(E) D$

where $N$ is the atomic density of GaAs crystal, $D$ is the ion fluence, and $S_{n}$ is $(d E / d x)_{n}$.

According to SRIM'2010 code the $\varepsilon$ value in our experiment exceeds $2 \times 10^{23} \mathrm{eV} / \mathrm{cm}^{3}$ for $\mathrm{Bi}$ ions with an energy of 200 $1600 \mathrm{keV}$. Moreover, the maximum elastic energy loss $S_{n}$ corresponds to $520 \mathrm{keV}-\mathrm{Bi}$ ions. It should be noted that the calculated level of deposited energy, is close to the critical level for creating an amorphous layer in GaAs, as it was discussed in the literature [32-35] on irradiation of GaAs with keV-MeV heavy ions at the room temperature.

Two basic models are proposed for amorphization of crystalline semiconductors under ion bombardment:

(i) A model of homogeneous amorphization (equivalent to a critical-energy-density model); according to this model the transformation to amorphous state occurs at some critical concentration of defects created by elastic ion collisions [36].

(ii) A heterogeneous model which assumes that accumulation of overlapping amorphized clusters in crystal matrix induces full amorphization [37].

It is believed that model (i) operates for light ions while model (ii) is realised for heavy ions. In our opinion, a heterogeneous model of amorphization mainly corresponds to our experimental conditions. Though, an accumulation of point defects can also contribute in amorphization in a crystal region enriched with defects formed by the pre-irradiation with electrons. These defects may supply nucleation sites for amorphous material and thus promote 

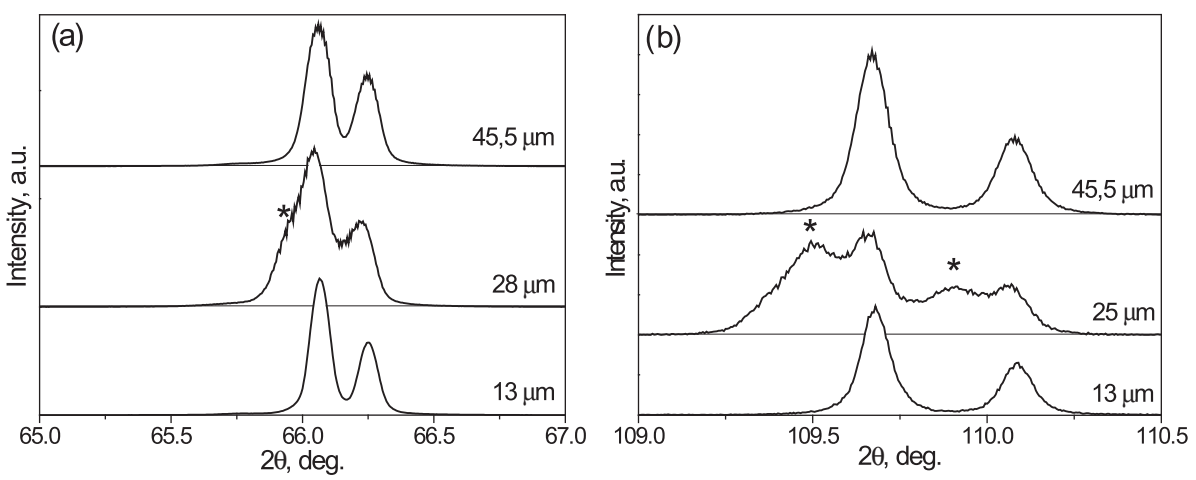

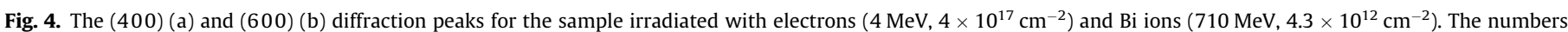

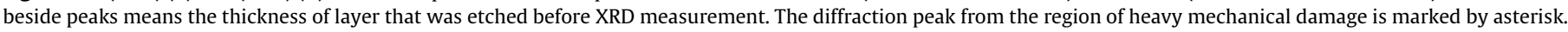

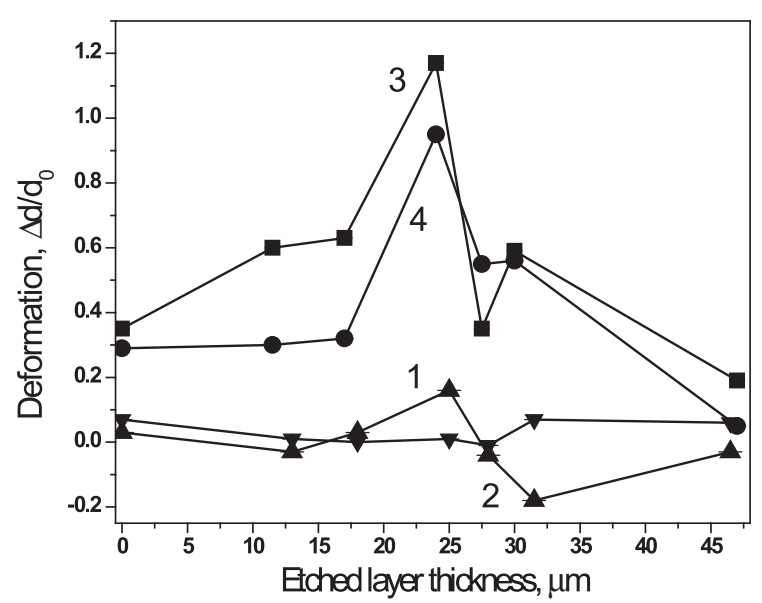

Fig. 5. The deformation of inter-plane distances of (400) (curves 1,3) and (600) (curves 2,4) diffraction peaks for the irradiated GaAs samples as a function of etched layer thickness. The samples irradiated with electrons only $(1,2)$ and double-irradiated with electrons and Bi ions $(3,4)$.

amorphization in comparison to the case of Bi irradiation only. Hence, one can suggest that the homogeneous amorphization can take place in the case of pre-damaged GaAs.

Herre et al. [2] have observed the formation of an amorphous layer in InP crystals at the depth of 19-21 $\mu \mathrm{m}$, i.e. close to $R_{p}$ after irradiation with $250-\mathrm{MeV} \mathrm{Xe}$ ions at a fluence of $(1-5) \times$ $10^{13} \mathrm{~cm}^{-2}$. In their experiment no any drastic displacement damage, as it was observed in present study (see Fig. 2(b)), has been revealed in the region of amorphous layer at the $R_{p}$ depth in Xe-irradiated InP crystals.

It should be stressed that our study deals with more heavy and energetic ions which produce more radiation defects in the end-of-range region. Regarding the difference between GaAs and InP, point defects in InP do not cause such a high lattice strain as it is the case for GaAs [38]. That is, a corresponding damaged subsurface layer in InP would not cause such a strong lattice expansion as in GaAs.

Besides, the GaAs crystal was irradiated with high fluence of swift electrons before SHI irradiation. As it was discussed above, the damaged layer at a depth corresponding to the end-of-range Bi ions may serve as a getter for vacancies generated by swift electrons uniformly over a whole thickness of the sample. In our opinion, in the case of GaAs crystals irradiated with Bi ions alone, a level of radiation damage at a fluence of $4.3 \times 10^{12}$ ions $/ \mathrm{cm}$ is under a threshold for the formation of deep amorphous layer. In addition, should be taken into account a difference in densities of amorphous and crystalline phase for InP and GaAs. Authors of
Ref. [39] studied the amorphization of crystalline InP during ion implantation. According to their data the final density of amorphous phase is almost exactly corresponds to that of c-InP. The density of $\alpha$-InP, in fact, is slightly (a fraction of percent) larger than that of c-InP. It is a bit surprising in view of fact that both $\alpha$-Si and $\alpha$-GaAs are less dense than their crystalline counterparts [38-40]. The experimentally determined density of $\alpha$-GaAs lies in the range of $4.98 \div 5.11 \mathrm{~g} / \mathrm{cm}^{3}$ [38,41], i.e. a few percent (from $5 \%$ to $6 \%$ ) less than that of c-GaAs ( $5.32 \mathrm{~g} / \mathrm{cm}^{3}$ [42]). This density's difference can initiate the irradiated layer swelling and microcracks formation in the deep amorpized region as it was observed in our study.

\section{Conclusions}

The selective chemical etching procedure has been used to study the structural transformations in GaAs crystals irradiated with electrons $\left(4 \mathrm{MeV}, 4 \times 10^{17} \mathrm{~cm}^{-2}\right.$ ) and $\mathrm{Bi}$ ions $(710 \mathrm{MeV}$, $4.3 \times 10^{12} \mathrm{~cm}^{-2}$ ). It has been found that the effects of Bi ion irradiation are displayed not in the region of high electronic energy loss but in a deeper region near the end-of-range for $\mathrm{Bi}$ ions. Two defect layers at a depth $25-30$ and $43-48 \mu \mathrm{m}$ have been revealed for the sample irradiated with $\mathrm{Bi}$ ions. A heavily-damaged region (microcracks) at a depth $30-40 \mu \mathrm{m}$ has been discovered in the sample double-irradiated with electrons and ions.

A relative change of lattice inter-plane distances $\Delta d / d$ at the different depth in GaAs crystal has been calculated from X-ray diffraction data. The change of $\Delta d / d_{0}$ is negligible and does not exceed $\pm 0.2 \%$ with the increase of the etched layer thickness in the sample irradiated with electrons. An additional irradiation with Bi ions results in lattice inter-plane distances increasing up to (0.3-0.4) $\%$ in the subsurface region of the sample. The level of lattice deformation increases with the etched layer thickness and achieves the highest value of $+(1.0-1.2) \%$ at the etched layer thickness of $\sim 25 \mu \mathrm{m}$. Taking into account the X-ray penetration depth (about $5 \mu \mathrm{m}$ for our measurements), we can estimate that the heavilydamaged region is located at a depth of about $25-30 \mu \mathrm{m}$. This depth corresponds to the region of maximum vacancies concentration and end-of-range $\mathrm{Bi}$ ions.

Two possible mechanisms have been proposed to explain the appearance of dramatic structural changes in pre-damaged GaAs crystals irradiated with swift $\mathrm{Bi}$ ions. The first one is based on the assumption that radiation swelling induces a mechanical strain in the GaAs subsurface region. In their turn, the layer enriched with $\mathrm{Bi}$ atoms and vacancies can also work as a getter for defects (preferably, vacancies) from an underneath crystal's volume produced on the stage of preliminary irradiation with electrons. Therefore, other region with a high concentration of vacancies is 
formed under the layer with stopped Bi atoms. In this situation the microcracks are developed in this region as a result of stress caused by the subsurface layer swelling.

On the other hand, as it was discussed in Section 3, a buried amorphous layer in the region of high nuclear energy loss can be formed in the pre-damaged with electrons GaAs crystal under $710 \mathrm{MeV}-\mathrm{Bi}$ ion irradiation. As the density of $\alpha$-GaAs is a few percent (about 6\%) less than that of c-GaAs, this effect can result in swelling, plastic flow and fracturing of material in this region. In the case of GaAs crystals irradiated with Bi ions alone, a level of radiation damage at a fluence of $4.3 \times 10^{12}$ ions $/ \mathrm{cm}^{2}$ is under a threshold for the formation of deep amorphous layer.

\section{Acknowledgments}

The study was supported partly by the State Committee on Science and Technology of the Republic of Belarus (grant T14KAZ002). The authors are grateful to Professor Yu. V. Bogatyrev (Scientific and Practical Materials Research Centre, National Academy of Sciences of Belarus) for sample irradiations with swift electrons.

\section{References}

[1] W. Wesch, E. Wendler, C.S. Schnohr, Damage evolution and amorph-ization in semiconductors under ion irradiation, Nucl. Instr. Meth. Phys. Res. B 277 (2012) 58-69.

[2] O. Herre, W. Wesch, E. Wendler, P.I. Gaiduk, F.F. Komarov, S. Klaumünzer, P. Meier, Formation of discontinuous tracks in single-crystalline InP by 250-MeV Xe-ion irradiation, Phys. Rev. B 58 (1998) 4832-4837.

[3] P.I. Gaiduk, F.F. Komarov, W. Wesch, Damage evolution in crystalline InP during irradiation with swift Xe ions, Nucl. Instr. Meth. Phys. Res. B 164-165 (2000) 377-383.

[4] P.I. Gaiduk, A.N. Larsen, C. Trautman, M. Toulemonde, Discontinous tracks in arsenic doped crystalline $\mathrm{Si}_{0.5} \mathrm{Ge}_{0.5}$ alloy layers, Phys. Rev. B 66 (2002) 045316.

[5] G. Szenes, Z.E. Horváth, B. Pécz, F. Pászti, L. Tóth, Tracks induced by swift heavy ions in semiconductors, Phys. Rev. B 65 (2002) 045206 (1-5).

[6] F.F. Komarov, P.I. Gaiduk, L.A. Vlasukova, A. Ju Didyk, V.N. Juvchenko, Track formation in germanium crystals irradiated with superhigh-energy ions, Vacuum 70 (2003) 75-79.

[7] F.F. Komarov, L.A. Vlasukova, V.N. Yuvchenko, T.V. Petlitzkaya, P. Zukowski, Peculiarities of the track formation in InP and GaAs crystals, Vacuum 78 (2005) 353-359.

[8] A. Kamarou, W. Wesch, E. Wendler, A. Undisz, M. Rettenmayr, Radiation damage formation, Phys. Rev. B 78 (2008) 054111 (1-12).

[9] C.S. Schnohr, P. Kluth, R. Giulian, D.J. Llewellyn, A.P. Byrne, D.J. Cookson, M.C Ridgway, Swift-heavy-ion-induced damage formation in III-V binary and ternary semiconductors, Phys. Rev. B 81 (2010) 075201 (1-9).

[10] B. Canut, N. Bonardi, S.M.M. Ramos, S. Della-Negra, Latent track formation in silicon single crystals irradiated with fullerenes in the electronic regime, Nucl. Instr. Meth. Phys. Res. B 146 (1998) 296-301.

[11] A. Colder, O. Marty, B. Canut, M. Levalois, P. Marie, X. Portier, S.M.M. Ramos, M. Toulemonde, Latent track formation in germanium irradiated with 20, 30 and $40 \mathrm{MeV}$ fullerenes in the electronic regime, Nucl. Instr. Meth. Phys. Res. B. (2001) 491-498.

[12] A. Colder, B. Canut, M. Levalois, P. Marie, X. Portier, S.M.M. Ramos, Latent track formation in GaAs irradiated with 20,30, and $40 \mathrm{MeV}$ fullerenes, J. Appl. Phys. 91 (2002) $5853(1-5)$.

[13] M.M. Belekar, A.M. Narsale, B.M. Arora, K.V. Sukhatankar, S.K. Dubey, V.P. Salvi, Distribution of radiation induced defects and modification of optical constants of GaAs implanted with high energy ${ }^{56} \mathrm{Fe}$ ions, Nucl. Instr. Meth. Phys. Res. B. 226 (2004) 301-308.

[14] X. Wang, Y. Zhang, Sh. Liu, Z. Zhao, Depth profiling by Raman spectroscopy of high-energy ion irradiated silicon carbide, Nucl. Instr. Meth. Phys. Res. B. 319 (2014) 55-61.
[15] A. Didyk, F. Komarov, L. Vlasukova, V. Yuvchenko, Yu. Bogatyrev, F. Korshunov, E. Gracheva, Structure changes in InP and GaAs crystals double irradiated with electrons and swift heavy ions, Vacuum 81 (2007) 1175-1179.

[16] A. Munoz-Yague, M. Bafleur, Shallow etching of GaAs using AB-solution under laser illumination, J. Cryst. Growth 53 (1981) 239-248.

[17] J.L. Weyher, F.D. Tichelar, H.W. Zandbergen, L. Macht, P.R. Hageman, Selective photoetching and transmission electron microscopy studies of defects in heteroepitaxial GaN, J. Appl. Phys. 90 (2001) 6105-6109.

[18] M.S. Abrahams, C.J. Buiocchi, Etching of dislocations on the low-index faces of GaAs, J. Appl. Phys. 36 (1965) 2855-2863.

[19] J.L. Weyher, J. Van de Ven, Selective etching of $\mathrm{GaAs}$ in $\mathrm{CrO}_{3}-\mathrm{HF}$ aqueous solutions, J. Cryst. Growth 78 (1986) 191-217.

[20] L.A. Vlasukova, Revealing the boundaries in epitaxial structures based on $A^{3} B^{5}$ compounds, Inorg. Mater. 29 (1993) 1431-1434.

[21] Sh. Mishra, S. Bhaumik, J. Kumar Panda, S. Ojha, A. Dhar, D. Kabiraj, A. Roy, Strain buildup in GaAs due to $100 \mathrm{MeV}$ Ag ion irradiation, Nucl. Instr. Meth. Phys. Res. B 316 (2013) 192-197.

[22] V.A. Kozlov, V.V. Kozlovski, Doping of semiconductors using radiation defects produced by irradiation with protons and alpha particles, Semiconductors 35 (2001) 735-761.

[23] F.P. Korshunov, Yu V. Bogatyrev, V.A. Vavilov, Vozdejstvie radiatsii na integral'nye microschemy, Minsk (1986) 254 (in Russian).

[24] J.P. Biersack, J.F. Ziegler, The Stopping and Ranges of Ions in Matter, vol. 1, Pergamon Press, New York, 1985.

[25] D.J. Stirland, B.W. Straughan, A review of etching and defect characterization of gallium arsenide substrate material, Thin Solid Films 31 (1976) 139-170.

[26] F.F. Komarov, Defect and track formation in solids irradiated by superhighenergy ions, Phys. Uspekhi 46 (12) (2003) 1253-1282.

[27] M.A. Kumakhov, F.F. Komarov, Energy Loss and Ion Ranges in Solids, Gordon and Breach, New York, London, Paris, 1981. p. 296.

[28] Y. Tagasaki, M. Morento, Cracking of epitaxial MnAs films on GaAs (001), J. Appl. Phys. 107 (2010) 023510 (5).

[29] F. Xiong, C.J. Tsai, T. Vreeland, T.A. Tombrello, C.L. Schwartz, S.A. Schwarz, Influence of substrate temperature on lattice strain field and phase transition in MeV oxygen ion implanted GaAs crystals, J. Appl. Phys. 65 (1991) 29642969.

[30] A. Pillukat, K. Karsten, P. Ehrhart, Point defects and their reactions in ēirradiated GaAs investigated by X-ray diffraction method, Phys. Rev. B 53 (1996) 7823-7835.

[31] C. Trautmann, M. Boccanfuso, A. Benyagoub, S. Klaumünzer, K. Schwartz, M. Toulemonde swelling of insulators induced by swift heavy ions, Nucl. Instr. Meth. Phys. Res. B 191 (2002) 144-148.

[32] J. Krynićki, H. Rzewuski, R. Grötzschel, A. Cluverie, Heterogeneous amorphization of Cd-implanted GaAs at room temperature, in: D.S Karpuzov, I.V. Hatardjiev, S.S. Todorov (Eds.), Proceedings of the International Conference on Ion Implantation and ion Beam Equipment, World Scientific, Singapore, New Jersey, London, Hong-Kong, 1991, pp. 96105.

[33] R.B. Drown, J.S. Williams, Crystalline-amorphous transformation in ionirradiated GaAs, Phys. Rev. B. 64 (2001) 155202 (6).

[34] E. Wendler, B. Breegor, Ch. Shubert, W. Wesch, Comparative study of damage production in ion implanted III-V compounds at temperatures from 20 to 240 K, Nucl. Instr. Meth. Phys. Res. B 147 (1999) 155-165.

[35] W. Wesch, E. Wendler, Z.S. Huçsain, S.M. Kluth, M.C. Ridgway, Rapid amorphization in $\operatorname{In}_{x} \mathrm{Ga}_{1-x}$ As alloys at temperatures between $15 \mathrm{~K}$ and $300 \mathrm{~K}$, Nucl. Instr. Meth. Phys. Res. B 242 (2006) 480-483.

[36] H.J. Stein, F.L. Vook, D.K. Brice, A. Border, T. Picraux, in: L.T. Chadderton, F.H. Eisen (Eds.), Proceedings of the 1st International Conference on Ion Implantation, Gordon and Breach, London, 1971, p. 17.

[37] F.F. Morehead, B.L. Crowder, A model for the formation of amorphous Si by ion bombardment, Rad. Effects 6 (1970) 27-32.

[38] C. Ascheron, A. Schindler, R. Flagmayer, G. Otto, A comparative study of swelling, strain and radiation damage of high-energy proton-bombarded GaAs, GaP, InP, Si and Ge single crystals, Nucl. Instr. Meth. Phys. Res. B 36 (1992) $163-172$.

[39] L. Cliche, S. Roorda, R.A. Masut, Persistent room-temperature relaxation of InP amorphized and compacted by MeV ion beams, Appl. Phys. Lett. (1994) 17541756.

[40] K. Laaziri, S. Roorda, L. Cliche, Density measurement of amorphous $\mathrm{Si}_{x} \mathrm{Ge}_{1-x}$ alloys, Nucl. Instr. Meth. Phys. Res. B 90 (1994) 438-441.

[41] M.L. Theye, A. Gheorghiu, H. Launois, Investigation of disorder effects in amorphous GaAs and GaP by EXAFS, J. Phys. C 13 (1980) 6569-6584.

[42] C.M.H. Driscoll, A.F.W. Willoughby, J.B. Mullin, B.W. Straughan. Gallium Arsenide and Related Compounds (Institute of Physics, London) 24 (1975) 275. 